\title{
Brand - Character Association and Attitude toward Brands in Movie Placements
}

\author{
Raghu Kurthakoti ${ }^{1}$, Siva K. Balasubramanian ${ }^{2}$ \& Suzanne Altobello ${ }^{3}$ \\ ${ }^{1}$ School of Global Business, Arcadia University, Glenside, PA, USA \\ ${ }^{2}$ Illinois Institute of Technology, Chicago, IL, USA \\ ${ }^{3}$ University of North Carolina Pembroke, Wilmington, NC, USA \\ Correspondence: Raghu Kurthakoti, School of Global Business, Arcadia Univeristy, 450 S Easton Road, Glenside, PA \\ 19038, USA. E-mail: kurthakotir@arcadia.edu
}

Received: January 24, 2016

Accepted: February 4, 2016

Online Published: March 18, 2016

doi:10.5430/ijba.v7n2p43

URL: http://dx.doi.org/10.5430/ijba.v7n2p43

\begin{abstract}
This study examines the impact of brand-character association on consumer attitude toward the placed brand. A $2 \times 2$ within subjects experiment, using a full-length movie as a stimulus, was conducted on a panel of student subjects to assess the interaction effect of character-brand valence on consumer attitude. Results support a significant interaction between character and brand valence. Analyses also indicate that congruency between character and brand valence enhances affective measures toward the placed brand, supporting the congruency theory and Meaning Transfer Model. Additionally, we found that brand familiarity mediates the character-valence interaction. Limitations and Implications of the studies were also discussed.
\end{abstract}

Keywords: movie product placements, negative placements, character and valence effects, brand attitude

\section{Introduction}

Various dimensions of the effectiveness of brand placements in movies have been studied: modality (Gupta and Lord, 1998), exposure time (Brennan, Dubas and Babin, 1999), prominence (Gupta and Lord, 1998; Yang and Roskos-Ewoldsen, 2007), familiarity (Brennan and Babin, 2004), level of placement (Yang and Roskos-Ewoldsen, 2007). These studies have significantly enhanced our knowledge of what makes a brand placement effective in terms of audience recall and recognition. Another important dimension for inquiry in assessing placement effectiveness is the brand-character association.

Few studies on brand placement have studied the effect of character association on viewers' evaluation of placements. (Exceptions include Russell and Stern, 2006; Yang and Roskos-Ewoldsen, 2007.) However, in the Russell and Stern (2006) study, the focus was to ascertain the effect of relationships with products (by the characters) and relationships with characters (by viewers) on the evaluation of placed products by viewers. In the Yang and Roskos-Ewoldsen (2007) study, the focus was on the level of placement and the centrality of placement to the plot on cognition and buying intention.

Studies on brand placements from a practitioner's perspective (Karrh, McKee, and Pardun, 2003; Russell and Belch, 2005) have found that both placement agencies and companies tend to place brands in such situations where the brands are showcased in a positive light.

Firms have refused to place their brands in such movies and television programs where the brand risks a potentially negative image and/or association, e.g. MasterCard in the movie Death Wish III, since the movie involved scenes of ghettoes and strong violence, and Anheuser Busch in the movie E.T. because the beer was supposed to be used for intoxicating a child and an alien (Segrave, 2004).

There is a famous quote attributed to Oscar Wilde: "There is only one thing worse than being talked about and that is not being talked about." This has been paraphrased and commonly used in the context of publicity as "Any publicity is good publicity." However, information available on brand placements implies that firms and placement agents do not subscribe to Wilde's quote. 
On the other hand, a study by Sorensen and Rasmussen (2004) on the impact of book reviews empirically revealed that negative reviews resulted in increased sales, suggesting that all publicity is good publicity.

Since brand placements share aspects of advertising and publicity (Balasubramanian, 1994), investigation into the nature of placement (positive and negative) on brand assessment by consumers is likely to be insightful both from an academic and a practitioner's viewpoint.

This study aims to extend the brand placement literature by attempting to understand the effect of a character's attitude toward a placed brand in the movie on the viewers' evaluation of the brand placement. We also aim to study the moderating/interaction effects of the viewers' familiarity with the brand; the viewer's evaluation of the character (positive or negative role) and the viewer's evaluation of the actor depicting the character in the movie (favorable or unfavorable actor).

\section{Literature Review}

\subsection{Genre Theory and Meaning Transfer Model}

Genre in movies is basically the classification based on attributes specific to one type of movies but not to other types. It is commonly used to categorize movies based on numerous criteria, like - story content (war movie), geographical location (Western), period (classic). Russell and Stern (2006) use genre theory to explain the relationship between the character and the placed brand. However, their model, which was aimed at sitcoms, focused on the valence of the character toward the product (i.e., whether the product was shown negatively or positively) and the strength of association with the product (weak/strong). But research has shown that a strong product character association and the centrality of placement to the plot have a higher impact on the brand recall and recognition (Balasubramanian, Karrh, and Patwardhan, 2006; Yang and Roskos-Ewoldsen, 2007). Moreover, unlike sitcoms, which allows viewers to become accustomed to characters and develop relationships with them - there are less opportunities to develop a relationship with movie characters.

Therefore, it is unlikely that the audience may identify strong and weak associations of a product with characters. On the other hand, the nature of a character an actor portrays in a movie (positive role or negative role) might impact the way a brand is associated with that character and might influence the overall evaluation of the placed brand. Additionally, since the movie is a one-time experience, unlike a televised series, a weak brand/character association may have a less positive impact on audience attitude toward the placement than a strong brand association with the character.

Additionally, McCracken's Meaning Transfer Model (1989) proposes that celebrity endorsers transfer meanings in a two-stage process. In the first stage, the meaning from the endorser are transferred to brands, and in the second stage, the meaning is transferred from the brand to the consumer. For such a transfer to a consumer to be effective, the celebrity endorser and the brand must be similar (McCracken, 1989 p.316).

This role of similarity between endorser and brand has been tested empirically in the advertising domain (Kamins and Gupta, 1994; Kirmani and Shiv, 1998; Misra and Beatty, 1990). In each of these studies, it was shown that congruence between the celebrity endorser and the product endorsed increased various advertisement measures, including recall and attitude toward endorsed product.

In developing an integrative framework for research on product placements, Balasubramanian et al. (2006) propose that incongruence in placements might trigger cognitive elaboration and thus facilitate cognitive measures like recall and recognition, while congruence might induce a peripheral route of processing and thereby result in a more positive attitude.

Russell (2002) found that incongruence between modality and plot connectedness resulted in higher memory outcomes but lower attitudes. Incongruent placements may attract greater attention and processing, thereby raising questions that may encourage the audience to discount the product placements.

When a brand is associated with a particular character in a movie, a similar process may follow. Brands that are associated congruently with the character may not elicit objections and may influence the audience through a peripheral route of persuasion (Petty and Cacioppo, 1986), thereby producing more positive attitudes toward the congruent brand. On the other hand, a brand whose placement is incongruent with a character may appear unusual, attract greater attention and processing, thereby producing less positive attitudes toward the incongruent brand.

Thus, the above discussion suggests an interaction between the valence of character associated with the brand and the character's valence toward the placed brand. This leads to our first hypothesis: 
H1: The attitude toward placement is more positive when there is congruence between the nature of character (positive/negative) and the character's valence toward the brand (positive/negative), compared to when there is a lack of such congruence.

\subsection{Parasocial Theory}

The attitude of viewers toward a placed brand is not merely a function of the character and valence interaction. Other variables might interfere in the process, such as attitude toward the actor.

Parasocial theory is used to explain the relationship viewers develop toward fictional characters conceived as real (Russell and Stern, 2006). Instances of research on such associations exist in marketing literature (e.g. Kozinets, 2001 - Star Trek culture of consumption). However, strong associations and relationships tend to develop when the viewers are exposed repeatedly to the same characters over a long period of time (as in sitcoms and other TV series).

On the other hand, during a movie viewing, the interaction between the character and audience is episodic in nature and can at best lead to development of attitude toward the character. Also, exposure to an actor (depicting a character) across movie instances will result in development of a relationship between audience and actor, with a sustaining attitude toward the actor independent of the current instance of exposure. This evaluation of actor might influence the character-valence interaction, as the attitude toward the actor tends to be stronger than the evaluation of the character he or she is portraying. A study by Tsai, Liang and Liu (2007) found that regardless of the brand awareness, audience attitude toward the actor influenced the attitude toward the placed brand.

This notion is also supported by literature on movies. Chang and Ki (2005), identifying success factors for movies, indicate that star actors can be regarded as ingredient brands in movies and play an extremely important role in attracting audiences to movies, often resulting in the success of the movies in which they perform.

Given this strong preference of the audience toward movie actors irrespective of the character played by the actor, we expect that audiences' attitude toward the actor (based on past exposure to the actor) will moderate the evaluation of the placed brand in the current instance. This leads us to our second hypothesis.

H2: The relationship hypothesized in $\mathrm{H} 1$ is moderated by consumers' attitude toward the actor as follows: Attitude toward placement is more positive when attitude toward the actor is favorable and when there is congruence between the character and valence toward the brand.

\subsection{Brand Familiarity and Product Placement Evaluation}

The above hypotheses were based on the premise that a brand placed in a movie is not familiar to the audience. However, most brand placements tend to be reinforcing and transformational in nature, rather than being informational (Auty and Lewis, 2004; Balasubramanian et al., 2006) and thus, the mere exposure effect seems to be a prominent factor in the conative effect of brand placement. This means that most brand placements in movies tend to be familiar to the audience. Research on the impact of familiarity with the placed brand on memory (recognition) has revealed a positive relationship even after adjusting for guesswork and constructive recognition (Brenan and Babin, 2004). It appears that brand familiarity plays a critical role in influencing audience evaluation of product placements.

Hoch and Ha (1986) propose that consumers exposed to an advertisement may not believe ad claims, but instead use the claims as a working hypothesis. Later they gather evidence in the light of this working hypothesis, suggesting a bias to confirm this hypothesis. In a similar fashion, a viewer with high familiarity toward the placed brand might look for clues and information that will result in a positive evaluation of the brand.

Karrh (1994) studied the effects of familiarity as a moderator for salience and evaluation of brands placed in movies. This study demonstrates that familiarity with product categories did moderate the relationship between brand exposure and brand salience.

The Hoch and Ha (1986) proposition of working hypothesis and the findings of Karrh (1994) suggest that the role of familiarity is stronger for product placements than for advertisements.

Advertisements are informational in nature and need not pertain to brands that are familiar to a significant portion of the audience. On the other hand, product placements are more transformational in nature and generally pertain to product categories and/or brands that are familiar to the consumers (Sapolsky and Kinney, 1994).

In addition to being transformational, the use of familiar brands for product placements helps audiences to infer meanings about the characters and the plot (Balasubramanian et al., 2006). Given such an important role of product placements in understanding the characters and other aspects of the editorial content of the program, familiar brands are more likely to elicit positive audience attitudes than unfamiliar brands. Familiar brands make the plot more realistic and may help the audience understand complex meanings associated with the program content. 
Studies in the advertising domain have focused on the effect of advertisement - brand congruity on brand attitude (Dahlèn and Lange, 2004; Dahlén,Lange, Sjödin, and Törn, 2005). Their research focuses on the role of congruence in attention and information processing. To that effect, they propose and empirically prove that brand familiarity results in increased attitude toward brand, an effect more pronounced for incongruent ads than for congruent ads. Congruence in familiar ads encourages boredom that might affect information processing and, consequently, brand evaluation. Incongruence, on the other hand, increases attention and thereby information processing, leading to higher brand evaluations. However, regarding brand placements, the brands are generally associated with a character, and as explained by the meaning transfer model (McCracken, 1989) congruence between endorser and brand results in smoother transfer of meaning.

Taken together, we would expect a familiar brand to result in higher brand attitude (as per the ad - brand congruency literature) and this effect would be stronger for congruent brands (based on the meaning transfer model). Therefore, we state our third hypothesis:

H3: The relationship hypothesized in $\mathrm{H} 1$ is moderated by consumers' familiarity with the placed brand as follows: Attitude toward placement is more positive when consumer familiarity with the placed brand increases and when there is congruence between character and valence toward the brand.

\section{Methodology}

A 2 (Character type - Positive/Negative) x 2 (Showcasing of brand in the movie - Positive/Negative) within subjects experiment was designed for the study, where respondents were exposed to all levels of the stimuli. This pool of respondents constituted the panel for the study. The biggest advantage of such a method is that the within group variance in the experiment is minimized drastically, since each individual acts as his/her own control and so eliminates the individual differences from the error variances. This also increases the power of the test and leads to better results (Girden, 1992; Stevens, 2002).

\subsection{Respondents}

A total of 62 undergraduate students were recruited from a university in the American Midwest; all were enrolled in various business courses (Marketing and Accounting). $56 \%$ of the respondents were male and 36\% were non-white.

Although a convenient sample and often subject to criticism, student samples have been used previously in consumer research and especially in research related to brand placement in movies (Babin and Carder, 1996; Nebenzahl and Secunda, 1993; Yang and Roskos Ewoldsen, 2007). This is because research on film audiences has shown that most of the people going to the movies are between the ages of 18 and 34 (Babin and Carder, 1996). Also, movie-going is a common activity for college students (Nebenzahl and Secunda, 1993). Therefore, the use of students as subjects for the study seems appropriate.

\subsection{Data Issues - Order Effect and Attrition}

Although repeated measure designs increase the power of a test and are preferred over random block designs, they are also associated with serious problems. Common problems associated with any within subjects repeated measures study include order effect and attrition (Girden, 1992; Stevens, 2002)

Order effect implies that since all respondents are exposed to the stimulus in the same order, the dependent measures might be affected. To address this problem, counterbalancing is suggested as a solution. Counterbalancing involves the assignment of the order of stimulus to each respondent randomly, such that an equal proportion of respondents receive the stimulus in each position. Order effect could only be addressed partially, given the nature of the study and the stimulus used. We could counterbalance only the order in which the subjects watched the movie, but could not counterbalance the order of the stimulus within a movie. Of our sample of 59 respondents, $49 \%$ watched the movie Rain Man first, and the remaining respondents watched Face/Off first. Thus, we were able to achieve a counterbalanced order of movie showing.

Attrition is a more serious problem in studies involving panels and repeated measures. This is because, unlike in cross-sectional studies, respondents cannot be added to the data collection pool at any random time during the study. Panel members are recruited at the beginning of the study and must remain a member of the study until its completion. Attrition in panels lead to missing data in the dataset for final analysis. Although imputation techniques are available to handle missing data, it is always preferable to have full information to analyze data.

Ribisl, Walton, Mowbray, Luke, Davidson II and Bootsmiller (1996) suggest eight strategies to minimize participant attrition in panel studies. Many of these strategies are applicable in situations where participants and researchers are geographically separated, where waves of data collection are conducted by telephonic interviews or through mail 
surveys and where studies involve extended time periods. However, some strategies suggested by Ribisl et al. (1996) might be adopted for our situation to minimize attrition. The first of these is to collect comprehensive information about the participants, including contact information, at the beginning of the study. This approach helps in tracking subjects during future data collection periods. The second strategy is to make the involvement convenient and rewarding for the participants. This can be achieved by minimizing the financial costs to participation and providing tangible and/or intangible rewards. The third strategy is to ensure that the study is not drawn out over an extended period of time.

To address attrition in our study, all these approaches were followed. During the recruitment phase, comprehensive information about the participants was collected, including full name, contact email, contact telephone number, age, gender, ethnicity, movie-watching behavior, etc.

During the study, participants were provided with both tangible and intangible awards. The tangible awards included a coupon that could be used to watch a movie at a local theater. This was provided to each and every respondent who participated and watched both movies used as a stimulus. At the end of the second movie, this movie coupon was handed out to the students. In addition to the movie coupon, every participant who completed all stages of the study (watching the movies, completing all the measurements) was eligible to win one of the five $\$ 20$ gift cards. In addition, students received extra course credit for their participation in the study. Other rewards included a free showing of a full-length movie (intangible) and a supply of snacks and drinks while watching the movie (tangible).

Finally, the students watched both movies at a time when school was in session, and they watched both movies within a span of 4 days. This interval between movies was reasonable given that the subjects watched an average of 15 movies in a month and the maximum 4-day gap between the two movies was within the normal range for most subjects.

At the end of the study we were left with 59 usable respondents out of the original 62 participants who signed up for the study. Thus, our strategy to address attrition worked.

\subsection{Stimulus}

The recruited panel members were shown two complete movies containing brand placements covering all the four treatment conditions.

The showing of a complete movie is recommended over showing movie clips containing placements (Babin and Carder, 1996; Balasubramanian et al., 2006). This is because recall measures of placements for short clips are not comparable to full movie exposure. Since in a natural setting, individuals are exposed to the entire movie before having to act upon the placements, using full-length movies makes the findings more generalizable.

The two movies shown were Rain Man and Face/Off. Table 1 shows the experimental design and the brands from these movies that were used as stimuli for the treatments. It should be noted that identifying placements associated with positive characters is easy. Also, it is relatively easy to identify placements that are shown positively in a movie. However, it is extremely difficult to identify those placements that are negatively associated with a negative character. For this purpose, a literature search was performed to identify possible candidates for operationalizing treatment condition 4. The researcher's own exposure to Rain Man indicated a possibility to operationalize two treatments for the study. Galician and Bourdeau (2004) indicated that Face/Off, with its display of negativity, was a contender to fit the remaining treatment conditions.

Table 1. Experimental design and stimulus

\begin{tabular}{llll}
\hline Valence/Character & Positive Character & Negative Character & Notes \\
\hline Positive Valence & \multicolumn{1}{c}{$\mathbf{1}$} & \multicolumn{3}{c}{$\mathbf{3}$} & Treatment code: \\
& Qantas Airlines & Chiclets & Stimulus placement: \\
& Rain Man & Face/Off & Movie: \\
& Raymond Babbit & Castor Troy & Character associated \\
& Dustin Hoffman & Nicholas Cage & Actor associated \\
\hline Negative Valence & $\mathbf{2}$ & \multicolumn{4}{c}{ Treatment code: } \\
& American Airlines & Seacraft boats & Stimulus placement: \\
& Rain Man & Face/Off & Movie: \\
& Raymond Babbit & Castor Troy & Character associated: \\
& Dustin Hoffman & John Travolta & Actor associated: \\
\hline
\end{tabular}


To confirm this and to identify the actual brand placements to be used for the study, two graduate students from engineering, who were not part of the study pool, were asked to serve as independent coders and evaluators for the placements in both movies. These coders were responsible for identifying the characteristics of the target placements in the movies. The feedback from the coders indicated that the placements shown in Table 1 represented the various treatment combinations.

In addition, a pretest was performed by showing selected movie clips portraying the brand placements to ten engineering undergraduate students who were not part of the study pool. The results indicated that valence toward the character was correctly operationalized across the four treatment conditions. However, the valence toward the brand was confirmed for only three of the four brands. As expected, the negative character - negative placement combination (Sea Craft boat) was not strong enough. However, the valence toward this particular placement was not significantly different from the midpoint of $4(\mathrm{M}=4.16, p>0.10)$. Supported by literature and the coder rating, and given the fact that the pretest evaluation was neutral for the placement, we included this as our final treatment.

\subsection{Measures}

Three different types of measures were collected at two different times to be used in the analysis:

\subsubsection{Dependent Measures}

The objective of the study is to assess the impact of character and brand valence interaction on viewer's attitudes toward brand placement. To this effect, subjects were asked about their attitude toward a set of brands (both target brands and a set of filler brands) before showing the movie. This represents their initial attitude toward the brand. A four item 7 point scale (Dislike/Like, Bad/Good, Unpleasant/Pleasant and Good quality/Bad quality) was used. This scale was adopted from Gardner (1985), who used the scale in the context of advertisements. The same scale with only the first three items was also used by Russell and Stern (2006).

The subjects completed the same scale for some of the placed brands (including the target brands) after they watched the movie. This indicates their attitude toward the brand after being exposed to the brand through product placement.

A difference of the summated scale of the two attitudes (before and after) indicates the change in attitude due to exposure and forms the dependent measure for the study.

\subsubsection{Subject-specific Covariate Measures}

The objective of the study is to assess the impact of placements on the change in attitude toward a brand. However, this difference might not be completely attributable to only the presence of the stimulus. Other variables might impact this change in attitude. Some of these variables include brand familiarity (Balasubramanian et al., 2006; Brennan and Babin, 2004; Nelson 2002), demographic information (Balasubramanian et al., 2006; Scott and Craig-Lees, 2003) and familiarity with movie and actor (Scott and Craig-Lees, 2003). These measures were collected using the established scales. Appendix 1 provides the sources and nature of the scales used.

\subsubsection{Subject Independent Covariate Measures}

In addition to subject factors, certain other factors independent of subjects might impact the change in attitude. Most notably, the movie and placement characteristics themselves might impact the change in attitude. Therefore, these variables were collected and used as covariates in the model. The variables included were movie length (minutes), placement exposure time, number of individual occurrences of the placement, placement modality (audio/visual/dual), presence of other brands, connectivity to the plot, etc.

Of these variables, some (e.g. movie length, placement exposure time) could not be used as covariates, as they were almost the same for all the treatments. This would result in less than full rank matrix for the independent variables, leading to biased estimates of regression slope co-efficients.

Tables 2 provides the descriptive statistics of the measures used for the study. 
Table 2. Descriptive statistics for variables used in the study

\begin{tabular}{|c|c|c|c|c|}
\hline & $\begin{array}{l}\text { Pos Char/ Pos } \\
\text { Val }\end{array}$ & $\begin{array}{l}\text { Pos Char/ Neg } \\
\text { Val }\end{array}$ & $\begin{array}{l}\text { Neg Char/ Pos } \\
\text { Val }\end{array}$ & $\begin{array}{l}\text { Neg Char/ Neg } \\
\text { Val }\end{array}$ \\
\hline \multirow[t]{2}{*}{ Familiarity with brand } & $2.60(1.89)^{\mathrm{a}}$ & $6.72(0.50)$ & $5.28(1.90)$ & $3.92(2.15)$ \\
\hline & $0.913^{\mathrm{b}}$ & 0.710 & 0.937 & 0.913 \\
\hline \multirow{2}{*}{$\begin{array}{l}\text { Attitude toward brand (Before } \\
\text { movie) }\end{array}$} & $4.28(0.94)$ & $5.63(1.26)$ & $4.93(1.38)$ & $4.88(1.24)$ \\
\hline & 0.982 & 0.967 & 0.952 & 0.969 \\
\hline \multirow{2}{*}{$\begin{array}{l}\text { Attitude toward brand (After } \\
\text { movie) }\end{array}$} & $5.28(1.21)$ & $5.02(1.38)$ & $4.91(1.34)$ & $5.25(1.42)$ \\
\hline & 0.971 & 0.984 & 0.946 & 0.966 \\
\hline \multirow[t]{2}{*}{ Familiarity with Actor } & \multicolumn{2}{|c|}{$5.34(1.85)$} & $6.64(0.66)$ & $6.72(0.67)$ \\
\hline & \multicolumn{2}{|c|}{0.916} & 0.771 & 0.828 \\
\hline \multirow{2}{*}{$\begin{array}{l}\text { Attitude toward actor associated } \\
\text { with brand }\end{array}$} & \multicolumn{2}{|c|}{$5.48(1.25)$} & $5.67(1.44)$ & $6.06(1.04)$ \\
\hline & \multicolumn{2}{|c|}{0.958} & 0.937 & 0.906 \\
\hline \multirow[t]{2}{*}{ Attitude toward Product Placement } & \multicolumn{2}{|c|}{$5.46(1.02)$} & \multicolumn{2}{|c|}{$4.95(1.44)$} \\
\hline & \multicolumn{2}{|c|}{0.942} & \multicolumn{2}{|c|}{0.963} \\
\hline \multirow[t]{2}{*}{ Attitude toward Movie } & \multicolumn{2}{|c|}{$5.46(1.19)$} & \multicolumn{2}{|c|}{$5.46(1.42)$} \\
\hline & \multicolumn{2}{|c|}{0.787} & \multicolumn{2}{|c|}{0.936} \\
\hline
\end{tabular}

Note: $\quad \mathrm{a}-$ Mean (Standard Deviation) $\quad \mathrm{b}-$ Cronbach's alpha

\section{Analysis and Results}

\subsection{Testing $\mathrm{Hl}$}

The objective of hypothesis 1 was to study the impact of interaction between character and valence on the change in consumer attitude toward a placed brand. For this $2 \times 2$ within subjects design, a repeated measures ANOVA could be performed to test the hypothesis (Stevens 2002). However as mentioned earlier, the change in attitude cannot be completely attributed to the treatment manipulations as other factors (e.g brand familiarity) have been shown to impact consumer attitudes (Balasubramanian et al., 2003; Karrh, 1994).

Therefore, a more effective approach would be to test for the treatment effects after controlling for other influencing variables. This implies that an ANCOVA needs to be performed. The common strategy adopted in an ANCOVA is to use a GLM framework where treatments are treated as fixed factors and covariates are included in the same model and tested (Gamst, Meyers and Guarino, 2008; Stevens, 2002). This approach works well for a between subjects design as the covariates are independent and unique across treatments. In a within subjects design, the assumption of independence is violated and so a repeated measure GLM is used in such cases to account for this dependence of observations.

However, in our particular situation, in addition to the problem of dependence of observations, other issues must be addressed. First, some covariates are constant across treatments (e.g. subject's gender and other demographic variables), whereas some covariates vary across treatments for the same subject (e.g. brand familiarity). Second, our particular set of stimuli has some variables that are constant for two of the treatments (Attitude toward actor treatments 1 and 2, Attitude toward the movie) and varies for the other two treatments. Third, we have many categorical variables as covariates (placement modality, gender, minority status, and familiarity with the movie), which might lead to further complications. These complications make use of the traditional repeated measure GLM for ANCOVA not viable.

An alternative has been suggested for performing ANCOVA (Gamst et al., 2008). This involves a two-step process: for the first step, an ordinary least square (OLS) regression is performed on the dependent variable using all the covariates as regressors pooling across the treatment conditions. The predicted values from this pooled regression are saved and this predicted value of the dependent variable is used as the adjusted dependent variable, and repeated measures ANOVA could be performed on the adjusted dependent variable. However, Gamst et al. (2008) suggest that we should check for homogeneity of regression before adopting this technique, since the OLS is performed after pooling responses across treatments. This check can be easily performed by running a GLM of the pooled data and checking for 
significant treatment group $\mathrm{x}$ covariate interaction. A non-significant interaction effect indicates that a particular covariate is not different across treatment groups (Gamst et al., 2008; p.460-61).

Given the complications with the nature of covariates, we adopted this approach wherein the repeated measure ANCOVA was performed in two steps. A homogeneity of regression test was conducted using the approach suggested by Gamst et al. (2008), and the results demonstrated that all the group x covariate interaction effects were non-significant $(p>.10)$, indicating the covariate effects were constant across treatments. Therefore we proceeded with the OLS analysis. Table 3 presents the results of the OLS regression of covariates on the dependent variable (change in attitude).

Table 3. Results of the pooled OLS regression used to obtain adjusted DV

\begin{tabular}{|c|c|c|c|c|}
\hline & b & SE & Std $\beta$ & $\mathbf{T}$ \\
\hline Intercept & 0.469 & 0.605 & & 0.776 \\
\hline Gender & 0.157 & 0.180 & 0.055 & 0.872 \\
\hline Minority Status & 0.124 & 0.179 & 0.042 & 0.691 \\
\hline Number of movies watched & 0.001 & 0.009 & 0.007 & 0.109 \\
\hline $\begin{array}{l}\text { Whether Rain Man was } \\
\text { watched first }\end{array}$ & 0.148 & 0.175 & 0.053 & 0.850 \\
\hline Familiarity of the Movie & 0.058 & 0.188 & 0.020 & 0.306 \\
\hline Attitude toward the Movie & 0.018 & 0.074 & 0.017 & 0.244 \\
\hline $\begin{array}{l}\text { Familiarity toward the } \\
\text { Actor }\end{array}$ & 0.084 & 0.077 & 0.091 & 1.087 \\
\hline Attitude toward the Actor & -0.033 & 0.091 & -0.030 & -0.367 \\
\hline $\begin{array}{l}\text { Attitude toward Product } \\
\text { Placements }\end{array}$ & 0.070 & 0.074 & 0.063 & 0.951 \\
\hline Brand Familiarity & $-0.175^{* *}$ & 0.048 & -0.288 & -3.633 \\
\hline $\begin{array}{l}\text { Visual Mode (Dummy } \\
\text { variable) }\end{array}$ & $-0.552 *$ & 0.241 & -0.197 & -2.286 \\
\hline $\begin{array}{l}\text { Audio Visual mode } \\
\text { (Dummy variable) }\end{array}$ & $-0.894 * *$ & 0.307 & -0.276 & -2.913 \\
\hline Model $\mathbf{R}^{2}$ & \multicolumn{4}{|c|}{0.227} \\
\hline$F(12,223)$ & \multicolumn{4}{|c|}{$5.45^{* *}$} \\
\hline
\end{tabular}

From Table 3 we find that of all the covariates, only placement modality and brand familiarity significantly impact the change in attitude toward a placed brand.

The coefficients for placement modality, indicates that 'visual only' and audiovisual placements have a significantly lower impact on the change in attitude compared to placements that are 'audio only'. These findings are consistent with Russell (2002), where audio placements were found to have a stronger impact on attitude compared to visual placements when the placement had high plot connectivity. Also, Gupta and Lord (1998) found that audio placements have a higher impact on cognitive measures than other placements. Given that most of our stimuli had high plot connectivity, these results support our findings.

Similarly, the negative coefficient for brand familiarity indicates that the higher a brand's familiarity, the lower the change in attitude. This result is interesting in our particular context, especially regarding our moderation hypothesis. In our hypothesis 3 we propose that brand familiarity will impact the attitude toward brand placements based on the working hypothesis theory (Hoch and Ha, 1986). Thus, a negative relationship between familiarity and attitude indicates that our expectations might be well-placed.

The predicted values from the preceding OLS regression were used as the dependent variable in the repeated measures ANOVA, and the results are presented in Tables 4 and 5

The results of the repeated measures ANOVA on the adjusted dependent variable indicates there is a significant interaction effect between character and valence, both at the univariate and multivariate levels, supporting hypothesis 1 . 
This interaction effect had significant power and high magnitude of effect, indicating the findings are not a chance event.

Table 4. Multivariate results of repeated measures ANOVA on the adjusted attitude change

\begin{tabular}{|c|c|c|c|c|c|c|c|c|}
\hline Effect & $\begin{array}{c}\text { Estimatioin } \\
\text { Method }\end{array}$ & Value & $\mathbf{F}$ & Hyp df & Error df & Sig. & $\begin{array}{c}\text { Effect } \\
\left(\eta^{2}\right)\end{array}$ & $\begin{array}{c}\text { Observed } \\
\text { Power" }\end{array}$ \\
\hline \multirow{4}{*}{ Character } & Pillai's Trace & .004 & $.235^{@}$ & 1.000 & 58.000 & .629 & .004 & .076 \\
\hline & Wilks' Lambda & .996 & $.235^{@}$ & 1.000 & 58.000 & .629 & .004 & .076 \\
\hline & Hotelling's Trace & .004 & $.235^{@}$ & 1.000 & 58.000 & .629 & .004 & .076 \\
\hline & Roy's Largest Root & .004 & $.235^{@}$ & 1.000 & 58.000 & .629 & .004 & .076 \\
\hline \multirow{4}{*}{ Valence } & Pillai's Trace & .861 & $360.760^{@}$ & 1.000 & 58.000 & .000 & .861 & 1.000 \\
\hline & Wilks' Lambda & .139 & $360.760^{@}$ & 1.000 & 58.000 & .000 & .861 & 1.000 \\
\hline & Hotelling's Trace & 6.220 & $360.760^{@}$ & 1.000 & 58.000 & .000 & .861 & 1.000 \\
\hline & Roy's Largest Root & 6.220 & $360.760^{@}$ & 1.000 & 58.000 & .000 & .861 & 1.000 \\
\hline \multirow{4}{*}{$\begin{array}{l}\text { Character * } \\
\text { Valence }\end{array}$} & Pillai's Trace & .886 & $452.808^{@}$ & 1.000 & 58.000 & .000 & .886 & 1.000 \\
\hline & Wilks' Lambda & .114 & $452.808^{@}$ & 1.000 & 58.000 & .000 & .886 & 1.000 \\
\hline & Hotelling's Trace & 7.807 & $452.808^{@}$ & 1.000 & 58.000 & .000 & .886 & 1.000 \\
\hline & Roy's Largest Root & 7.807 & 452.808@ & 1.000 & 58.000 & .000 & .886 & 1.000 \\
\hline
\end{tabular}

Note: @ Exact Statistic * Computed using alpha $=0.05$

Table 5. Univariate results of repeated measures ANOVA on the adjusted attitude change

\begin{tabular}{lrrrrrrr}
\hline \multicolumn{1}{c}{ Source } & $\begin{array}{c}\text { Type III } \\
\text { SS }\end{array}$ & Df & MSS & F & $\boldsymbol{p}$ & $\begin{array}{c}\text { Effect } \\
\left.\mathbf{\eta}^{\mathbf{2}}\right)\end{array}$ & $\begin{array}{c}\text { Observed } \\
\text { Power }^{*}\end{array}$ \\
\hline Character & .021 & 1 & .021 & .235 & .629 & .004 & .076 \\
Error(Character) & 5.288 & 58 & .091 & & & & \\
\hline Valence & 28.204 & 1 & 28.204 & 360.760 & .000 & .861 & 1.000 \\
Error(Valence) & 4.534 & 58 & .078 & & & & \\
\hline Character* Valence & 50.265 & 1 & 50.265 & 452.808 & .000 & .886 & 1.000 \\
Error(Character*Valence) & 6.438 & 58 & .111 & & & & \\
\hline
\end{tabular}

a - The epsilon value was estimated at 1.00 and so the results presented were based on analysis assuming sphericity

Note: $*$ Computed using alpha $=0.05$

To understand the nature of this interaction, we performed a series of t-tests on the difference in attitude, comparing it with a test value of 0 . The results shown in Table 6 indicate that congruent treatment conditions had a significantly positive change in attitude, whereas non-congruent treatment conditions had either a significant negative change in attitude (as in case of treatment 2 - positive character/negative valence) or had no change in attitude (as in case of treatment 3 - negative character/positive valence).

A graphical representation of the interaction makes the finding clearer, as can be seen in Figure 1 .

Table 6. Results of t-tests on change in attitude toward placed brand

\begin{tabular}{cccc}
\hline Treatment & $\begin{array}{c}\text { Difference in attitude } \\
\text { (Att. After - Att. Before) }\end{array}$ & t statistic & $P$ \\
\hline Posi Char/Pos Val (1) & 1.00 & 6.67 & $<0.001$ \\
Pos Char/Neg Val (2) & -0.61 & -3.22 & $<0.01$ \\
Neg Char/Pos Val (3) & -0.21 & -0.127 & $>0.50$ \\
Neg Char/Neg Val (4) & 0.36 & 2.31 & $<0.05$ \\
\hline
\end{tabular}




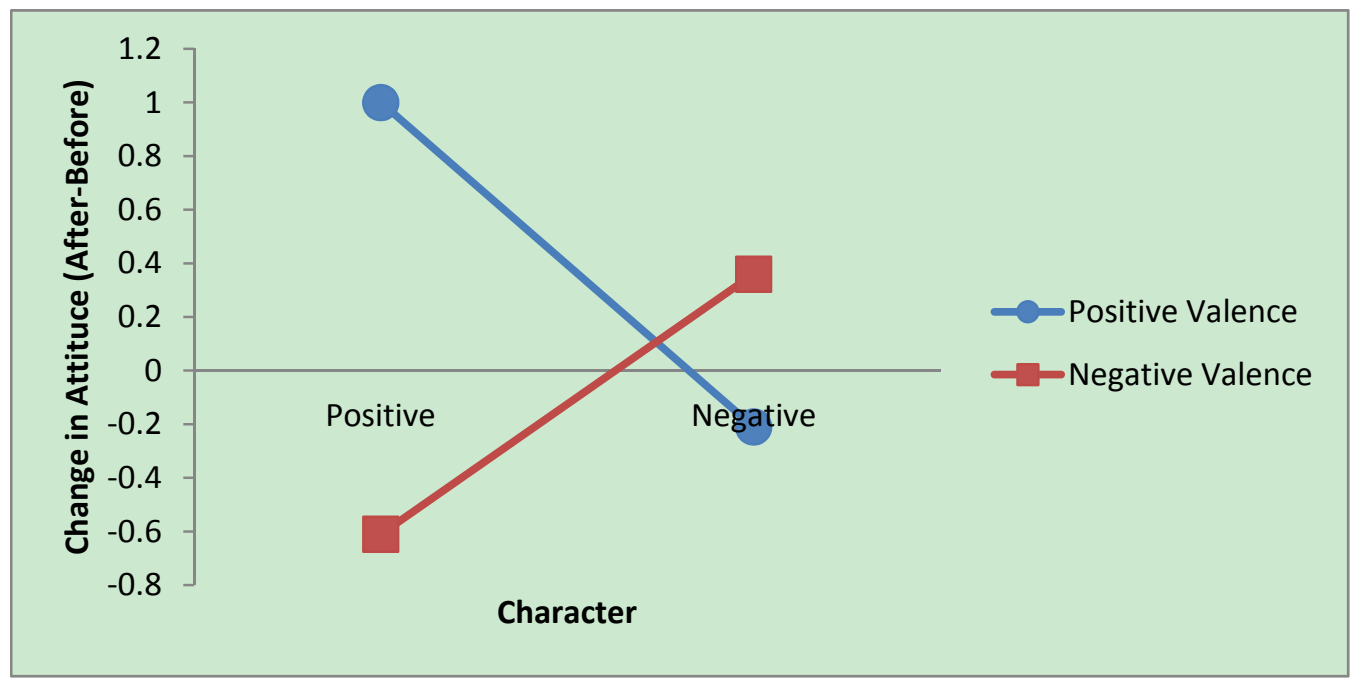

Figure 1. Interaction effects of character and valence on difference in attitude

From Table 6 and Figure 1 we find that, as long as there is congruence between character and valence, viewers experience a positive change in their attitude toward the placed brands.

\subsection{Testing $\mathrm{H} 2$ and $\mathrm{H} 3$}

The next two hypotheses pertain to testing the moderating effect of different variables on the change in attitude toward a placed brand. The most common way of testing moderation is to use an interaction term in an OLS regression model and test for the significance of the parameter estimate of this cross-product term (Baron and Kenny, 1986; Judd, Kenny, and McClelland, 2001; Judd, McClelland, and Smith, 1996).

However, this approach is valid and acceptable for a between subjects design, as it meets the assumption of independence of observations. However, since a within subjects design does not meet this criteria, using a pooled OLS model with an interaction term will not serve the purpose of testing for moderation.

Judd et al. (2001) and Judd et al. (1996) provide a methodological approach for handling moderation and mediation effects in a within subjects design, using a series of regression analyses. Given the nature of our data and the aim of the study, the approach suggested by Judd et al. (2001) was adopted to test for moderation and mediation effects.

This approach uses regression on differences of scores between treatments of interest to test for mediation and moderation.

The testing of hypotheses 2 and 3 was performed by analyzing the following regression model.

$$
\mathrm{Y}_{\text {Diff } \mathrm{i}}=\mathrm{d}_{0}+\mathrm{d}_{1} \mathrm{AA}_{\mathrm{SC} \mathrm{i}}+\mathrm{d}_{2} \mathrm{AA}_{\text {Diff } \mathrm{i}}+\mathrm{d}_{3} \mathrm{BF}_{\mathrm{SC} \mathrm{i}}+\mathrm{d}_{4} \mathrm{BF}_{\text {Diff } i}+\mathrm{e}_{\mathrm{i}}
$$

Where, for the ith individual,

$Y_{\text {Diff }}$ is the difference in dependent variable scores between treatments of interest. This was calculated by subtracting change in attitude for non-congruent treatments from change in attitude for congruent treatments.

$\mathrm{AA}_{\mathrm{SC}}$ is the centered sum of the scores of attitude toward actor for congruent and non-congruent treatments. This term was calculated by adding the attitude toward actor for congruent treatments (treatments 1 and 4 ) and non-congruent treatments (treatments 2 and 3 ) and centering the sum using its mean.

$\mathrm{AA}_{\text {Diff }}$ is the difference in the scores of attitude toward actor for congruent and non-congruent treatments. This was calculated by subtracting the attitude toward actor for non-congruent treatments (treatments 2 and 3 ) from the attitude toward actor for congruent treatments (treatments 1 and 4).

$\mathrm{BF}_{\mathrm{SC}}$ is the centered sum of the scores of brand familiarity for congruent and non-congruent treatments. This term was calculated by adding the brand familiarity scores for congruent treatments (treatments 1 and 4) and non-congruent treatments (treatments 2 and 3 ) and centering the sum using the mean of the sum. 
$\mathrm{BF}_{\text {Diff }}$ is the difference in the scores of brand familiarity for congruent and non-congruent treatments. This was calculated by subtracting the brand familiarity for non-congruent treatments (treatments 2 and 3 ) from the attitude toward actor for congruent treatments (treatments 1 and 4).

$\mathrm{e}$ is the random error term assumed to be normally distributed with mean 0 and constant variance.

$\mathrm{d}_{0}, \mathrm{~d}_{1}, \mathrm{~d}_{2}, \mathrm{~d}_{3}$ and $\mathrm{d}_{4}$ represent estimates of regression slope co-efficients.

One should note that centered sum is used in regression model (Eq 1). This is recommended for the following reason (Judd et al., 2001):

If the sum of the mediating variable across treatments is centered, then the intercept value indicates an overall effect over and above any mediation/moderation due to the concomitant variables. Thus, a significant $\mathrm{d}_{0}$ along with a significant $\mathrm{d}_{2}$, and/or $\mathrm{d}_{4}$ indicates partial mediation. A non-significant $\mathrm{d}_{0}$ with a significant $\mathrm{d}_{2}$, and/or $\mathrm{d}_{4}$ indicates complete mediation, provided the mean difference in $\mathrm{X}$ between two treatments is significant. Also, the differencing term for the two variables (attitude to actor and brand familiarity) were not centered because a zero difference between the congruent and non-congruent treatments has significant meaning of its own, and so the presence of zero in the variable is insightful.

This model in equation 1 could be slightly modified to test hypotheses 2 and 3 independently. The results of the OLS regression of equation 1, along with modifications to test for hypotheses 2 and 3 independently, are provided in Table 7.

Table 7. Overall moderation for congruent and non-congruent treatments

\begin{tabular}{|c|c|c|c|c|}
\hline Model & $\begin{array}{c}\text { Model1 } \\
\text { b (s.d) }\end{array}$ & $\begin{array}{c}\text { Model2 } \\
\text { b (s.d) }\end{array}$ & $\begin{array}{c}\text { Model3 } \\
\text { b (s.d) }\end{array}$ & $\begin{array}{c}\text { Model4 } \\
\text { b (s.d) }\end{array}$ \\
\hline Intercept & $1.42^{* * *}(0.13)$ & $0.36(2.31)$ & $-0.02(0.70)$ & $-0.02(0.70)$ \\
\hline Brand Familiarity Sum Centered & - & - & $0.01(0.09)$ & $-0.02(0.11)$ \\
\hline Brand Familiarity Difference & - & - & $-0.37^{* * *}(0.11)$ & $-0.38^{* * *}(0.11)$ \\
\hline Actor Attitude Sum Centered & $-0.06^{*}(0.04)$ & $0.08(0.11)$ & - & $0.08(0.12)$ \\
\hline Actor Attitude Difference & $0.07(0.08)$ & $-0.28(0.24)$ & - & $-0.28(0.24)$ \\
\hline Composite Brand Familiarity (Congruence) & - & $-0.40^{* * *}(0.12)$ & - & - \\
\hline Composite Brand Familiarity (Non-congruence) & - & $0.36^{* *}(0.18)$ & - & - \\
\hline $\mathrm{R}^{2}$ & 0.08 & 0.22 & 0.20 & 0.22 \\
\hline$F$ & 2.36 & $4.03^{* *}$ & $7.06^{* * *}$ & $4.03^{* * *}$ \\
\hline DF for $F$ ratio (df num, df Den) & 2,56 & 4,54 & 2,56 & 4,54 \\
\hline
\end{tabular}

Note:

1. The different models depicted in the above table are as follows

Model1 - Testing H2 alone using adjusted Change in attitude (after-before)

Model 2 - Testing $\mathrm{H} 2$ alone using brand familiarity as a covariate

Model3 - Testing $\mathrm{H} 3$ alone

Model4 - Testing H2 and H3 simultaneously (represented by Eqn 5)

2. $* p<.10 \quad * * p<.05 * * * p<.01$

The results indicate that overall, hypothesis 2 is not supported, either when tested alone or when tested simultaneously with hypothesis 3 . As Table 7 shows, in model 2, we find that the effect on attitude change is due to brand familiarity alone. This is also justified by our OLS regression on the pooled data (Table 3), where we did not find a significant effect of attitude toward actor on the attitude change. One possible reason for such results could be the nature of the attitude toward the actors expressed by the subjects. A look at Table 2 indicates that across all the treatments, the 
attitude toward the actor is fairly similar. This similarity might have resulted in a non-significant parameter estimate for $\mathrm{d}_{1}$ and/or $\mathrm{d}_{2}$ in equation 5 , leading to failure of support for the hypothesis.

However, we discover interesting findings related to hypothesis 3 , and the results are consistent irrespective of whether hypothesis 3 was tested alone or simultaneously with hypothesis 2 . Since the simultaneous estimation of hypotheses 2 and 3 did not significantly differ from the tests on hypotheses 2 and 3 individually, all discussion will be based on the model testing hypotheses 2 and 3 simultaneously.

Model 4 in Table 7 indicates that, contrary to expectation, brand familiarity has a mediating effect on change in attitude. Specifically, the brand familiarity variable completely mediates the differences in change in attitude between congruent and non-congruent treatments. The results indicate that brand familiarity has a negative impact on the difference in attitude change toward the placed brand. The higher an individual's familiarity with a brand, the lower the difference in attitude change across congruent and non-congruent treatments. This finding is consistent with our hypothesis 3 , which postulates that higher brand familiarity of congruent treatments will lead to higher attitude change. From Table 2, we see that the brand familiarity scores for the congruent treatments (treatments 1 and 4) are significantly lower than the familiarity scores for the non-congruent treatments (treatments 2 and 3 ). The t-test comparing the means of the brand familiarity between congruent and non-congruent groups indicated that the two means were statistically different from each other $\left(M_{C o n}=6.52, M_{N C}=12.00, p<.001\right)$. Therefore, a negative effect of brand familiarity indicates that the difference in attitude change (between congruent and non-congruent treatments) is less, owing to lower familiarity scores of congruent treatments. This finding is consistent with Balasubramanian et al. (2006), who propose that audiences use familiar brands to make inferences about character/story, which results in higher affective outcomes of placements. Thus, our analysis supports hypothesis 3 but not hypothesis 2 .

\section{Discussion}

In our study we hypothesized that an interaction between the nature of character and the character's valence will have an impact on the extent of change in attitude toward the placed brand. To this effect, our study provided strong support for hypothesis 1 , where a significant interaction was observed between character and valence. Further, this interaction supported the source congruity concept, whereby treatments with congruence between the character and valence led to a significant positive change in attitude over treatments with non-congruence.

Russell (2002) found support that congruency between modality and plot connectedness resulted in more positive attitudes, whereas incongruence led to higher cognitive measures. When we analyzed the cognitive measures for the brands under each of the treatments, we found that for the congruent brands (Qantas Airlines and Sea-craft) the recall rates were $12 \%$ and $8 \%$, respectively. However, for the non-congruent brands (American Airlines and Chiclets), the recall rates were much higher, at $39 \%$ and $52 \%$ respectively. This provides support for the proposition offered by Balasubramanian et al. (2006), as well as the findings of Russell (2002). A similar pattern emerges for the recognition of these four brands as well. Recognition for Seacraft (46\%) was much lower than the recognition for Chiclets (68\%). However, the recognition rates for Qantas and American Airlines were identical at $80 \%$. This can be explained by the fact that both American Airlines and Qantas Airlines were present in the same scene of the movie, and recognition of one might have triggered the recognition of the other.

In addition, although not formally stated as hypothesis in the study, we found that of the two independent factors (Character and Valence), only Valence had a significant main effect. Specifically, the marginal means for the valence shows that brands in positive valence exhibit a positive change in attitude $(M=0.529, \mathrm{SD}=0.038)$ compared to brands shown in negative valence $(M=-0.162, \mathrm{SD}=0.029)$.

Thus, our findings on hypothesis 1 provide empirical support to the view subscribed to by practitioners (Karrh et al., 2003) that negative placements adversely impact consumer attitude toward the placed brand. However, as our analysis shows, negative placements are not necessarily detrimental. As long as negative placements are matched with the character, they do exhibit a positive effect on consumer attitude toward placed brand. This is because a negative placement with a negative character in a movie brings about congruence between the endorser and the brand, thereby creating similarity. This similarity appears natural in its flow and might induce a peripheral route of persuasion. Additionally, such naturally-appearing placements are favorably evaluated by consumers, resulting in positive attitudinal change toward the placed brand (Russell, 2002).

In addition to the primary expectation of a strong interaction effect, we had hypothesized two moderating effects on the interaction between character and valence. These were the attitude toward the actor and the familiarity toward the brand. 
Our study did not support the attitude toward the actor moderation (hypothesis 2). This is probably due to the fact that for each of the treatments, the attitude toward the actor was positive and fairly similar. Such close evaluation of different actors associated with the brands leads to less variability across treatments and might have resulted in non-significant results for moderation. A paired $t$ test on the attitude toward actor under congruent and non-congruent treatment conditions revealed that there was only a marginally significant difference in attitude toward the actors for these treatments groups $(d=0.384, p<.10)$. Such low differences across treatment groups might have resulted in non-significant moderation effects.

On the other hand, we found support for a mediating effect of brand familiarity on the change in attitude between congruent and non-congruent treatments. Specifically, we found that a lower brand familiarity with congruent treatments resulted in a lower difference in the attitude change between congruent and non-congruent treatments. These findings are consistent with the findings in the advertising domain on ad-brand congruency (Dahlèn and Lange, 2004; Dahlén et al., 2005). Through our results, we find that due to the higher degree of familiarity of incongruent brands, the difference between congruent and incongruent treatments was less, resulting in a negative effect of brand familiarity on the differences in attitude change.

Also, given the nature of the brand familiarity variable, the presence of mediation seems not merely plausible, but likely. One of the assumptions concerning mediation is that the mediating variable temporally precurs the dependent variable. In our situation, the mediating variable, a measure on the subject's familiarity with the brand, is very likely to have occurred first, before inducing any change in attitude toward the brand. Further, the brand familiarity is not just influencing the magnitude of the attitude change, but is involved in the attitudinal change, as evidenced by our pooled regression results in Table 3. Thus, it appears that the role of brand familiarity in product placements is one of mediation rather than moderation, especially when the relationship is between the character, valence and the attitude toward the brand. In addition, as we find in the propositions of Balasubramanian et al. (2006), consumers use familiar brands to make inferences about characters and the plot. Thus, familiarity is actively assisting the consumers in their consumption of the program, and therefore is more likely to mediate the relationship between character, valence and attitude toward placement

The results are consistent with our expectation that a higher degree of familiarity among congruent brands will result in a higher change in attitude, as compared to non-congruent brands.

\section{Implications, Limitations and Future Research}

\subsection{Theoretical Implications}

This study provides an empirical test for the effect of congruence in placements. Practitioners and researchers have indicated that negative placements generally tend to evoke negative responses (Karrh et al., 2003; Russell and Stern, 2006). However, our study demonstrates that as long as there is congruence between the character and negative placement, the placements evoke positive responses.

This study extends the study of Russell (2002) by providing additional support to the congruency theory and how it impacts cognitive and affective measures differently. We show that congruence increases affective measures and incongruence increases cognitive measures when the congruence is between the nature of character and the nature of brand portrayal.

This study further extends the literature from the advertising domain (Kamins and Gupta, 1994; Kirmani and Shiv, 1998; Misra and Beatty, 1990) and confirms that the meaning transfer model and source congruity concepts hold true in the context of product placements in movies as well. The study empirically demonstrates how and under what circumstances the affective measures are impacted in the case of product placements in movies.

This research expands on the product placement literature by dissecting the role of brand familiarity in facilitating affective measures toward the placed brand. Product placement literature has predominantly focused on the role of brand familiarity in cognitive measures (Balasubramanian et al., 2006; Brennan and Babin, 2004). However, our research extends this literature by demonstrating the role of familiarity on affective measures toward product placements.

\subsection{Managerial Implications}

First, our study provides empirical support for the belief that negative placements result in negative attitudes toward the placed brand. However, it also demonstrates situations under which negative placements encourage positive attitudes toward placed brands. This can be achieved by bringing about congruence between the character and his/her valence toward the placed brand. Thus, a firm that desires to associate its brand with a negative character in a movie 
will be better off showing their brand in a negative light with the character rather than showing the brand in a positive light.

Second, with the growing trend of famous celebrities appearing in roles with negative shades (e.g. Clive Owen in the movie Inside Man, Morgan Freeman in the movie Wanted, Leonardo Di Caprio in The Wolf of Wall Street etc.) it is becoming important to understand how such characters could be effectively used for carrying product placements. Going by the traditional logic that positive placements yield positive results, audiences will associate characters with brands presented in a positive light. But as our study shows, such associations will not result in a significant positive change in attitude toward the placed brand. However, if these characters are associated with a brand in a negative light, then the audience may be more likely to experience a positive impact of such placements on their attitude toward the brand.

Finally, our study demonstrates that the presence of a competing brand need not necessarily harm another brand. If a competing brand is associated with a character but in a non-congruent way, the competing brand might be damaged without affecting the target brand. This is evident with the use of two competing airlines associated with a single character in the same movie in the same scene (treatments 1 and 2). Our study provides insights into ways in which firms can gain advantage over the competition by placing a competitor's brand in an incongruent situation as opposed to a congruent situation.

\subsection{Limitations and Future Research}

Nature of sample subjects used - Although research (Nebenzahl and Secunda 1993) supports the use of student samples in research related to movies, this method does limit the extent of generalizability of the findings to the general population.

Dependent measures used - Our study tested the effect of congruence between character and valence on only affective measures. However, practicing marketers are more interested in the conative effect of such placements on actual behavior. Given the nature of our study, this could not be tested for two reasons - stimulus used and timing of the study.

First, the stimuli used in the study were airline services (treatments 1 and 2) as well as a speedboat (treatment 4). Given the subject pool for the study, personal finances would limit the subjects from expressing their actual behavior.

Second, the study was conducted when school was in full session and not during a vacation time. Thus, it was not possible to test for actual behavior toward the brands, as this would entail travelling via an airline, an unlikely activity for a student when school is in full session.

Another limitation of the study pertains to the nature of the stimulus that was used, especially with regards to the actors associated with the brands. We find from Table 2 that subjects rated the actors associated with the character extremely similarly. This probably resulted in the lack of support for $\mathrm{H} 2$. Our primary interest was to study the interaction effect between character and valence, and so efforts were made to identify the right stimulus that covered various levels of the basic treatment sets. Additionally, given our intention to use real-world stimuli for the study, we could not adequately control for this variable.

Given our limitations in the present study, we identify several ways in which our research could be extended. First, use of strict manipulation on actor attitude could lead to better testing of $\mathrm{H} 2$ to see whether moderation/mediation occurs. This might be difficult to achieve using real-world stimuli, so one might have to develop fictional stimuli to correctly manipulate the attitude toward the actor to test this hypothesis.

A logical extension of our study would be to assess the effect of character - valence interaction on conative measures (buying behavior). Thus, one could test whether this change in attitude persists and results in actual purchasing of the brands that were congruently placed vis-à-vis incongruently placed brands. This might again involve developing fictional stimuli for each treatment condition using brands from same product category to study the conative effects.

\section{Conclusion}

An experimental study using a panel of student subjects was initiated to understand the effect of character and its valence toward a placed brand on consumers' evaluation of brand. Based on Genre Theory (Russell and Stern, 2006), the Meaning Transfer Model (McCracken, 1989) and the working hypothesis proposition (Hoch and Ha, 1986) a set of hypotheses were presented and tested using a within subjects model.

Our study showed that congruence between the nature of character and its valence toward the placed brand increases attitude toward placed brand, but reduces recall. We also found support that the audience's familiarity with the placed brand mediates this relationship. In addition, theoretical and managerial implications of the research were discussed. 


\section{References}

Auty, S., \& Lewis, C. (2004). Exploring Children's Choice: The Reminder Effect of Product Placement. Psychology and Marketing, 21(9), 699-716. http://dx.doi.org/10.1002/mar.20025

Babin, L. A., \& Carder, S. T. (1996), Advertising via the Box Office: Is Product Placement Effective?. Journal of Promotion Management, 3(1/2), 31-51. http://dx.doi.org/10.1300/J057v03n01_03

Balasubramanian, S. K. (1994). Beyond Advertising and Publicity: Hybrid Messages and Public Policy Issues. Journal of Advertising, 23(4), 29-46. http://dx.doi.org/10.1080/00913367.1943.10673457

Balasubramanian, S. K., Karrh, J. A., \& Patawardhan, H. (2006). Audience Response to Product Placements: An Integrative Framework and Future Research Agenda. Journal of Advertising, 35(3), 115-141. http://dx.doi.org/10.2753/JOA0091-3367350308

Baron, R. M., \& Kenny, D. A. (1986). The moderator-mediator variable distinction in social psychological research: Conceptual, strategic, and statistical considerations. Journal of Personality and Social Psychology, 51(6), 1173-1182. http://dx.doi.org/10.1037/0022-3514.51.6.1173

Brennan, I., \& Babin, L. A. (2004). Brand Placement Recognition: The Influence of Presentation Mode and Brand Familiarity. Journal of Promotion Management, 10(1/2), 185-202. http://dx.doi.org/10.1300/J057v10n01_13

Brennan, I., Dubas, K. M., \& Babin, L. A. (1999). The Influence of Product-Placement Type and Exposure Time on Product-Placement Recognition. International Journal of Advertising, 18, 323-337.

Burke, R. R., \& Srull, T. K. (1988, June). Competitive Interference and Consumer Memory of Advertising. Journal of Consumer Research, 15, 55-68. http://dx.doi.org/10.1086/209145

Calder, B. J., \& Sternthal, B. (1980, May). Television Commercial Wear-out: An Information processing View. Journal of Marketing Research, 17, 173-186. http://dx.doi.org/10.2307/3150928

Chang, B., \& Ki, E. (2005). Devising a Practical Model for Predicting Theatrical Movie Success: Focusing on the Experience Good Property. Journal of Media Economics, 18(4), 247-269. http://dx.doi.org/10.1207/s15327736me1804_2

Coen, R. (2008). Insider's Report: Robert Coen Presentation on Advertising Expenditures. December 2008, MAGNA Insights.

d'Astous, A., \& Chartier, F. (2000). A study of factors affecting consumer evaluations and memory of product placements in movies. Journal of Current Issues and Research in Advertising, 22(2), 31-40. http://dx.doi.org/10.1080/10641734.2000.10505106

Dahlèn, M., \& Lange, F. (2004). To Challenge Or Not To Challenge: Ad-Brand Incongruency and Brand Familiarity. Journal of Marketing Theory and Practice, 12(3), Summer, 20-35. http://dx.doi.org/10.1080/10696679.2004.11658522

Dahlén, M., Lange, F., Sjödin, H., \& Törn, F. (2005). Effects of Ad-Brand Incongruency. Journal of Current Issues and Research in Advertising, 27(2), Fall, 1-12. http://dx.doi.org/10.1080/10641734.2005.10505178

DeLorme, D. E., \& Reid, L. N. (1999). Moviegoers Experiences and Interpretations of Brands in Films Revisited. Journal of Advertising, 28, Summer, 71-90. http://dx.doi.org/10.1080/00913367.1999.10673584

Ford, G. T., Smith, D. B., \& Swasy, J. L. (1990). Consumer Skepticism of Advertising Claims: Testing Hypotheses from Economics of Information. Journal of Consumer Research, 16(1), 433-441.

Forehand, M. R., \& Grier, S. (2003). When is Honesty the Best Policy? The Effect of Stated Company Intent and Consumer Skepticism. Journal of Consumer Psychology, 13(3), 349-356.

Galician, M., \& Bourdeau, P. G. (2004). The Evolution of Product Placements in Hollywood Cinema: Embedding High-Involvement "Heroic" Brand Images. Journal of Promotion Management, 10(1/2), 15-36. http://dx.doi.org/10.1300/J057v10n01_03

Gamst, G., Meyers, L. S., \& Guarino, A. J. (2008). Analysis of Variance Designs: A Conceptual and Computational Approach with SPSS and SAS. Cambridge University Press, NY.

Gardner, M. P. (1985, May). Does Attitude to the Ad Affect Brand Attitude Under a Brand Evaluation Set?. Journal of Marketing Research, 22, 192-198. http://dx.doi.org/10.2307/3151364 
Girden, E. R. (1992). ANOVA Repeated Measures. The Quantitative Applications in the Social Sciences, (84). Sage Publications Inc. CA.

Glass, Z. (2007). The effectiveness of product placement in Videogames. Journal of Interactive Advertising, 8(1), 1-27. http://dx.doi.org/10.1080/15252019.2007.10722134

Gupta, P. B., \& Gould, S. J. (1997). Consumers Perceptions of the Ethics and Acceptability of Product Placement in Movies: Product Category and Individual Differences. Journal of Current Issues and Research in Advertising, 19(1), 37-50. http://dx.doi.org/10.1080/10641734.1997.10505056

Gupta, P. B., \& Lord, K. (1998). Product Placement in Movies: The Effect of Prominence and Mode on Audience Recall. Journal of Current Issues and Research in Advertising, 20(1), 47-59. http://dx.doi.org/10.1080/10641734.1998.10505076

Gupta, P. B., Balasubramanian, S. K., \& Klassen, M. L. (2000). Viewers Evaluations of Product Placements in Movies: Public Policy Issues and Managerial Implications. Journal of Current Issues and Research in Advertising, 22(2), 41-52. http://dx.doi.org/10.1080/10641734.2000.10505107

Hoch, S. J., \& Ha, Y. (1986, Sept.). Consumer Learning: Advertising and the Ambiguity of Product Experience. Journal of Consumer Research, 13, 221-233. http://dx.doi.org/10.1086/209062

IBM SPSS Statistics software, Version 19, copyright of IBM Corporation, Somers, NY.

Judd, C. M., Kenny, D. A., \& McClelland, G. H. (2001). Estimating and Testing Mediation and Moderation in Within-Subject Designs. Psychological Methods, 6(2), 115-134. http://dx.doi.org/10.1037/1082-989X.6.2.115

Judd, C. M., McClelland, G. H., \& Smith, E. R. (1996). Testing Treatment by Covariate Interactions when Treatment varies Within Subjects. Psychological Methods, 1(4), 366-378. http://dx.doi.org/10.1037/1082-989X.1.4.366

Kamins, M. A., \& Gupta, K. (1994). Congruence between Spokesperson and Product Type: A Matchup Hypothesis Perspective. Psychology and Marketing, 11(6), 569-586. http://dx.doi.org/10.1002/mar.4220110605

Karrh, J. A. (1994). Effects of Brand Placements in Feature Films. In Karen Whitehill King (Ed.), Proceedings of the 1994 Conference of the American Academy of Advertising (pp. 90-96). Athens, GA: American Academy of Advertising.

Karrh, J. A., McKee, K. B., \& Pardun, C. J. (2003). Practitioners' Evolving Views on Product Placement Effectiveness. Journal of Advertising Research, 43(2), 138-149. http://dx.doi.org/10.2501/JAR-43-2-138-149

Kirmani, A., \& Shiv, B. (1998). Effects of Source Congruity on Brand Attitudes and Beliefs: The Moderating Role of Issue-Relevant Elaboration. Journal of Consumer Psychology, 7(1), 25-47. http://dx.doi.org/10.1207/s15327663jcp0701_02

Kozinets, R. V. (2001, June). Utopian Enterprise: Articulating the Meanings of Star Trek's Culture of Consumption. Journal of Consumer Research, 28, 67-88. http://dx.doi.org/10.1086/321948

McCracken, G. (1989, Dec.). Who Is the Celebrity Endorser? Cultural Foundations of the Endorsement Process. Journal of Consumer Research, 16, 310-321. http://dx.doi.org/10.1086/209217

Misra, S., \& Beatty, S. E. (1990). Celebrity spokesperson and brand congruence: An assessment of recall and affect. Journal of Business Research, 21(2), 159-173. http://dx.doi.org/10.1016/0148-2963(90)90050-N

Nebenzahl, I. D., \& Secunda, E. (1993). Consumers' Attitudes toward Product Placement in Movies. International Journal of Advertising, 12(1), 1-11.

Petty, R. E., \& Cacioppo, J. T. (1986). The Elaboration Likelihood Model of Persuasion. In Leonard Berkowitz (Ed.), Advances in Experimental Social Psychology (Vol. 19, pp. 123-205). New York: Academic Press.

Ribisl, K., Walton, M. A., Mowbray, C. T., Luke, D. A, Davidson II, W. S., \& Bootsmiller, B. J. (1996). Minimizing Participant Attrition in Panel Studies Through The Use of Effective Retention and Tracking Strategies: Review and Recommendations. Evaluation and Program Planning, 19(1), 1-25. http://dx.doi.org/10.1016/0149-7189(95)00037-2

Russell, C. A. (2002). Investigating the Effectiveness of Product Placement in Television Shows: The Role of Modality and Plot Connection Congruence on Brand Memory and Attitude. Journal of Consumer Research, 29(3), 306-318. http://dx.doi.org/10.1086/344432 
Russell, C. A., \& Belch, M. (2005). A Managerial Investigation into the Product Placement Industry. Journal of Advertising Research, 45(1), 73-92. http://dx.doi.org/10.1017/S0021849905050038

Russell, C. A., \& Stern, B. B. (2006). Consumers, Characters and Products: A Balance Model of Sitcom Product Placemetn Effects. Journal of Advertising, 35(1), 7-21. http://dx.doi.org/10.2753/JOA0091-3367350101

Sapolsky, B. S., \& Kinney, L. (1994). You Oughta be in Pictures: Product Placements in the top grossing Films of 1991. In Karen Whitehill King (Ed.), Proceedings of the 1994 Conference of the American Academy of Advertising (p. 89). Athens, GA: American Academy of Advertising.

Scott, J., \& Craig-Lees, M. (2003). Audience Characteristics and Product Placement Effects. ANZMAC 2003 Conference Proceedings, Adelaide.

Segrave, K. (2004). Product Placement in Hollywood Films: A History. McFarland \& Co., Inc., Publishers, NC.

Sorensen, A. T., \& Rasmussen, S. J. (2004). Is Any Publicity Good Publicity? A Note on the Impact of Book Reviews. Working Paper, Stanford University, CA. Retrieved from $\mathrm{http}: / / \mathrm{www} . s t a n f o r d . e d u / \sim a s o r e n s e /$ papers/bookreviews.pdf

Stevens, J. (2002). Applied Multivariate Statistics for the Social Sciences (4th ed.). Lawrence Erlbaum Associates Publishers, NJ.

Tsai, M., Liang, W., \& Liu, M. (2007). The Effects of Subliminal Advertising on Consumer Attitudes and Buying Intentions. International Journal of Management, 24(1), 3-14.

Whittler, T. E., \& DiMeo, J. (1991). Viewers Reaction to Racial Cues in Advertising Stimuli. Journal of Advertising Research, 31(6), 37-46.

Yang, M., \& Roskos-Ewoldsen, D. R. (2007). The Effectiveness of Brand Placements, Explicit and Implicit Memory, and Brand-Choice Behavior. Journal of Communication, 57(3), 469-489. http://dx.doi.org/10.1111/j.1460-2466.2007.00353.x 